\title{
MODELling AND ANALYSIS OF SYMMETRIC PoWer Converter for Aircraft APPLiCATIONS
}

CORCAU, J.I. \& DINCA, L.

Abstract: Last year's tendencies in aerospace industries are to reduce commercial aircraft weight. Reducing aircraft weight implies the necessity to have more electrical systems on board and to replace hydraulic and pneumatic systems with electric systems. This work focuses on a power conversion system composed by a SEPIC converter and a Cuk converter, both connected in parallel and with interleaved functioning. Output voltage for the entire system is \pm 270 VDC. For both converters one deduced design equations and one choose components values according these equations. Finally, one simulated the system functioning in MATLAB/SIMULINK. Simulation results show a good output voltage stabilisation on the entire load domain, with excellent results in continuous conduction mode.

Key words: power converters, modelling, analysis, aircraft
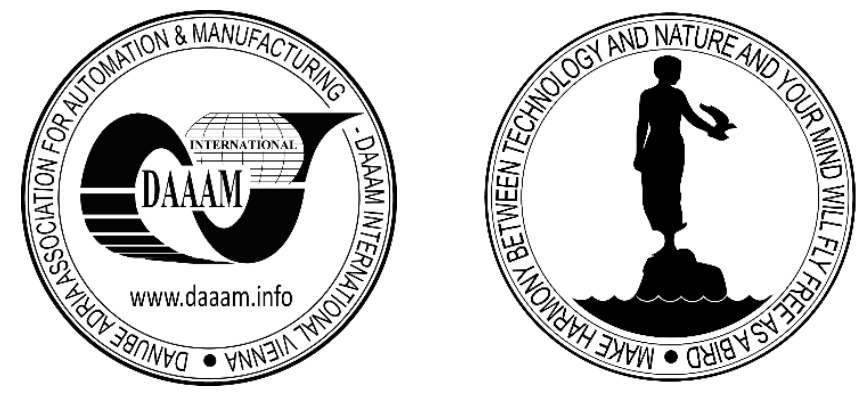

Authors' data: Associate Professor PhD. Corcau, J[enica] Ileana; Associate Professor PhD Dinca, L[iviu], University of Craiova, Decebal street, no.107, Craiova, Romania, jcorcau@elth.ucv.ro, ldinca@elth.ucv.ro

This Publication has to be referred as: Corcau, J[enica] I[leana] \& Dinca, L[iviu] (2020). Modelling and Analysis of Symmetric Power Converter for Aircraft Applications, Chapter 02 in DAAAM International Scientific Book 2020, pp.015-032, B. Katalinic (Ed.), Published by DAAAM International, ISBN 978-3-902734-27-3, ISSN 1726-9687, Vienna, Austria

DOI: $10.2507 /$ daaam.scibook.2020.02 


\section{Introduction}

One of the main problems in aeronautical industry is to reduce new commercial aircraft weight. Lighter aircraft means lower fuel consumption, lower costs and lower greenhouse gas emissions. So, lighter aircraft is an important desiderate for air transport companies and also a compromise with de sustainable development. Researchers pay a permanent effort in this direction (Ayres, J.; Richards, R.; et al 2006; Eid, A.; El-Kishky, H. et al. 2010; Corcau, J. I. \& Dinca, L. 2012).

One way to reduce the electric system weight is to increase the nominal network voltage. At the same power currents decrease and further the necessary conductor diameters decrease. In conclusion, high electric network voltage means low electric network weight. In the past decades one could observe a rapid increase of the on board DC network voltage. From 28 VDC one increased to 270 VDC in present and the tendencies are to increase further to $540 \mathrm{VDC}$ but in the version $\pm 270 \mathrm{VDC}$ (Corcau, J. I. \& Dinca, L. 2015, Kwon, J. M. \& Kwon, B.H. 2009).

Symmetric converter idea becomes from the necessity to convey more and more energy in the modern aircraft electric network. Replacing hydraulic and pneumatic systems with electric system means the power conveyed on the hydraulic and pneumatic network will be transferred on the electric network. Thinking only the hydraulic servos feeding energy transferred to electric network one leads to an overload in the electric network. So, the purpose is to deliver this energy to the loads at the minimum possible network weight, using different network voltages. The power source considered in this paper is a fuel cell. Fuel cells are increasingly used on aircraft due to certain advantages. It is expected new APUs to be manufactured using fuel cells and in the medium future even electric propulsion to use fuel cells as power sources. Power converter systems has to be designed respecting aerospace standards for energy quality and electromagnetic interference (EMI) - see RTCA DO-160 standard for environmental conditions and testing procedures for aerospace equipment's (Delos, J. 2010).

System performance criteria are: weight, volume and efficiency: so the purpose is to obtain a system with the highest power density possible (W/kg). First, one has to reduce the magnetic components dimensions, because the main contribution to the converter weight is paid to these components. Second, using rapid commutation semiconductors as power MOSFETs, IGBTs and ultra rapid diodes or SiC diodes one can increase the conversion system performances (Delos, J. 2010; Rahimi, A. M \& Emadi, A. 2009 ). By the other hand, using a fuel cell as power source is a challenge for the entire system. Due to its voltage-current characteristic, voltage drops as load increases, so the conversion system is not set to a constant functioning point. Moreover, fuel cell has limitations concerning current ripple and does not allow inverse current. Both have a negative impact on the fuel cell lifetime (Tseng, K.C. \& Liang, T.J. 2004; Liu, C.; Johnson, A.; \& Lai, J.-S. 2004).

\section{System structure}

Purpose of this system is to provide a stabilised output voltage necessary for the on board consumers. This converter contains two converters with complementary 
characteristics: SEPIC converter provides +270 VDC and Cuk converters provides 270 VDC.

In figure 1.a one shows the SEPIC converter scheme and in figure 1.b one shows Cuk converter scheme. Both converters use a capacitor as tank element to transfer the energy from input to output, unlike most used converters that use a coil.

Along topologies advantages, these converters have also the disadvantage of a big passive components number 2 coils and 2 capacitors. This fact increases circuit analysis and implementation complexity.

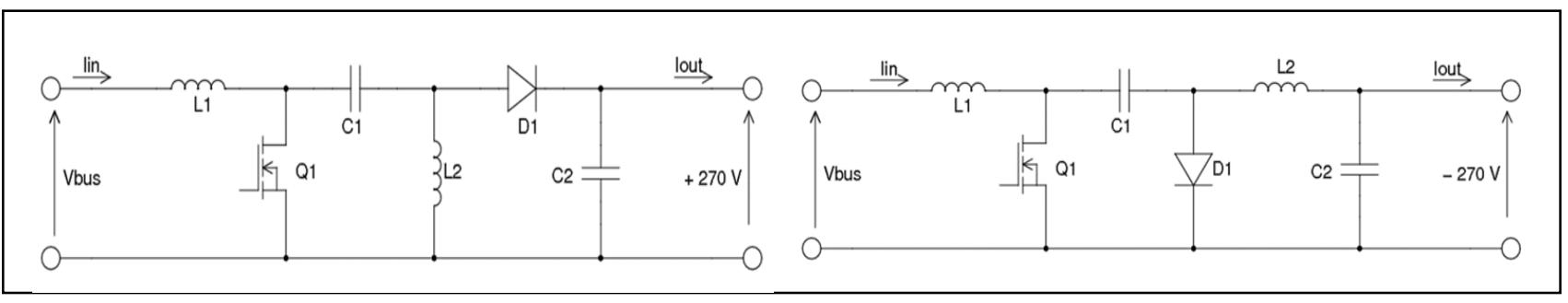

Fig. 1a. Sepic converter scheme

Fig. 1b. Cuk converter scheme

\subsection{SEPIC converter steady state circuit model}

In order to analyse and simulate the SEPIC converter behaviour one uses traditional method of variable topology, replacing commutation elements with zero load or short-circuit elements with respect the command signal applied to the commutation element $\mathrm{Q}_{1}$. This model is based on a reference with constant voltage, obtaining a constant commutation time. So, one can identify two different states of the circuit at equilibrium. Replacing semiconductors with closed circuits leads to two possible states: $\mathrm{Q}_{1}$ closed, $\mathrm{D}_{1}$ open and $\mathrm{Q}_{1}$ open and $\mathrm{Q}_{2}$ closed (see figure 2).

Figure 2 presents these equivalent circuits during the two states of the SEPIC converter. In the following one will use the notations: $i_{1^{-}}$current through $\mathrm{L}_{1}$ coil, $i_{2^{-}}$ current through $\mathrm{L}_{2}$ coil, $v_{1}$ voltage on the $\mathrm{C}_{1}$ capacitor, $v_{2}$ voltage on the $\mathrm{C}_{2}$ capacitor, equal with the output voltage. Using Kirchhoff theorems, one deduces coil voltages and currents through capacitors. Below equations result, where $\mathrm{D}$ is the duty cycle of the PWM signal that controls the commutation element $\mathrm{Q}_{1}$. $\mathrm{D}$ is time when $\mathrm{Q}_{1}$ is in conduction and $\mathrm{D}^{\prime}$ is time when $\mathrm{Q}_{1}$ is blocked.

When Q1 is in conduction, during ton time coil currents increase, voltage source $E$ transfers energy to coil $L_{1}$ and capacitor $C_{1}$ transfers energy to coil $L_{2}$. In the same time $\mathrm{C}_{2}$ feeds the load. When $\mathrm{Q}_{1}$ is blocked during toff period, coils currents decrease, current through $\mathrm{L}_{1}$ charges $\mathrm{C}_{1}$ and $i_{2}$ adds to $i_{1}$ to feed load and to charge $\mathrm{C}_{2}$ (Delos, J. 2010; Erickson, R. W. \& Maksimovic, D. 2004).
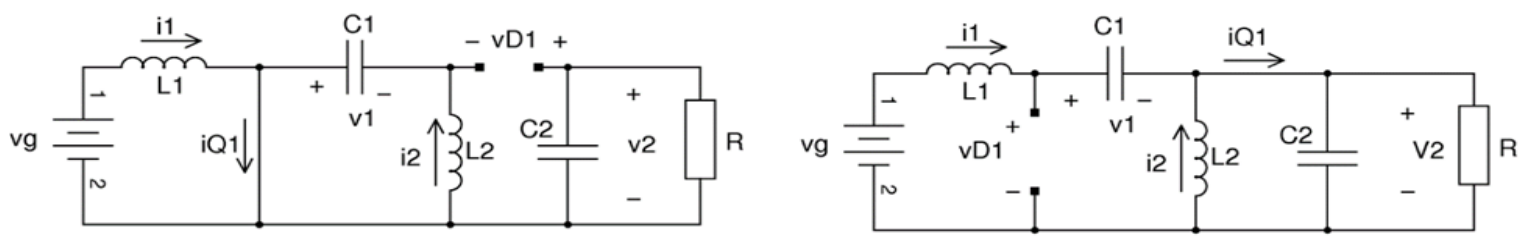

Fig. 2. SEPIC converter circuit in the two states $t_{\text {on }}$ and $t_{\text {off }}$ 
$v_{L_{1}}=v_{g}$

$v_{L_{2}}=v_{1}$

$i_{C_{1}}=-i_{2}$

$i_{C_{2}}=-\frac{v_{2}}{R}$

One can suppose commutation ripples amplitude of $i_{1}(t), i_{2}(t), v_{1}(t)$ and $v_{2}(t)$ are small with respect continuous current components $I_{1}, I_{2}, V_{1}, V_{2}$. In this approximation, relations (1) become (Erickson, R. W. \& Maksimovic, D. 2004).

$v_{L_{1}}=V_{g}$

$v_{L_{2}}=V_{1}$

$i_{C_{1}}=-I_{2}$

$i_{C_{2}}=-\frac{V_{2}}{R}$

In $t_{\text {off }}$ period coils voltages and capacitors currents are

$v_{L_{1}}=v_{g}-v_{1}-v_{2}$

$v_{L_{2}}=-v_{2}$

$i_{C_{1}}=i_{1}$

$i_{C_{2}}=i_{1}+i_{2}-\frac{v_{2}}{R}$

Next step is to consider small ripple in relations (3) and these become

$v_{L_{1}}=V_{g}-V_{1}-V_{2}$

$v_{L_{2}}=-V_{2}$

$i_{C_{1}}=I_{1}$

$i_{C_{2}}=I_{1}+I_{2}-\frac{V_{2}}{R}$

Further, one can equalize continuous current components or mediate values for currents and voltages using equations (2) and (4). Also, one supposes medium coils voltages and capacitors currents are 0. Results (Erickson, R. W. \& Maksimovic, D. 2004):

$<v_{L_{1}}>=D V_{g}+D^{\prime}\left(V_{g}-V_{1}-V_{2}\right)$

$<v_{L_{2}}>=D\left(V_{1}\right)+D^{\prime}\left(-V_{2}\right)$

$<i_{C_{1}}>=D\left(-I_{2}\right)+D^{\prime} I_{1}$ 
$<i_{C_{2}}>=D\left(-\frac{V_{2}}{R}\right)+D^{\prime}\left(I_{1}+I_{2}-\frac{V_{2}}{R}\right)$

where $D$ and $D^{\prime}$ is duty cycle that defines commutation interval while $t_{o n}=D T$ and $t_{\text {off }}=D^{\prime} T$. Relations (5) become (5')

$0=D V_{g}+D^{\prime}\left(V_{g}-V_{1}-V_{2}\right)$

$0=D\left(V_{1}\right)+D^{\prime}\left(-V_{2}\right)$

$0=D\left(-I_{2}\right)+D^{\prime} I_{1}$

$0=D\left(-\frac{V_{2}}{R}\right)+D^{\prime}\left(I_{1}+I_{2}-\frac{V_{2}}{R}\right)$

After some operations, this system solution, for the continuous current components of coils and capacitors voltages is

$V_{1}=V_{g}$

$V_{2}=V_{g} \frac{D}{D^{\prime}}$

$I_{1}=I_{2} \frac{D}{D^{\prime}}=\frac{V_{g}}{R}\left(\frac{D}{D^{\prime}}\right)^{2}$

$I_{2}=\frac{V_{2}}{R}=\frac{V_{g}}{R} \frac{D}{D}$

DC conversion ratio for the Sepic converter is $M(D)=\frac{V_{2}}{V_{g}}=\frac{D}{D^{\prime}}=\frac{D}{1-D}$. Equations (2),

(4) and (6) are used to draw coils currents and capacitors voltages represented in figure 3 (Delos, J. 2010; Erickson, R. W. \& Maksimovic, D. 2004).

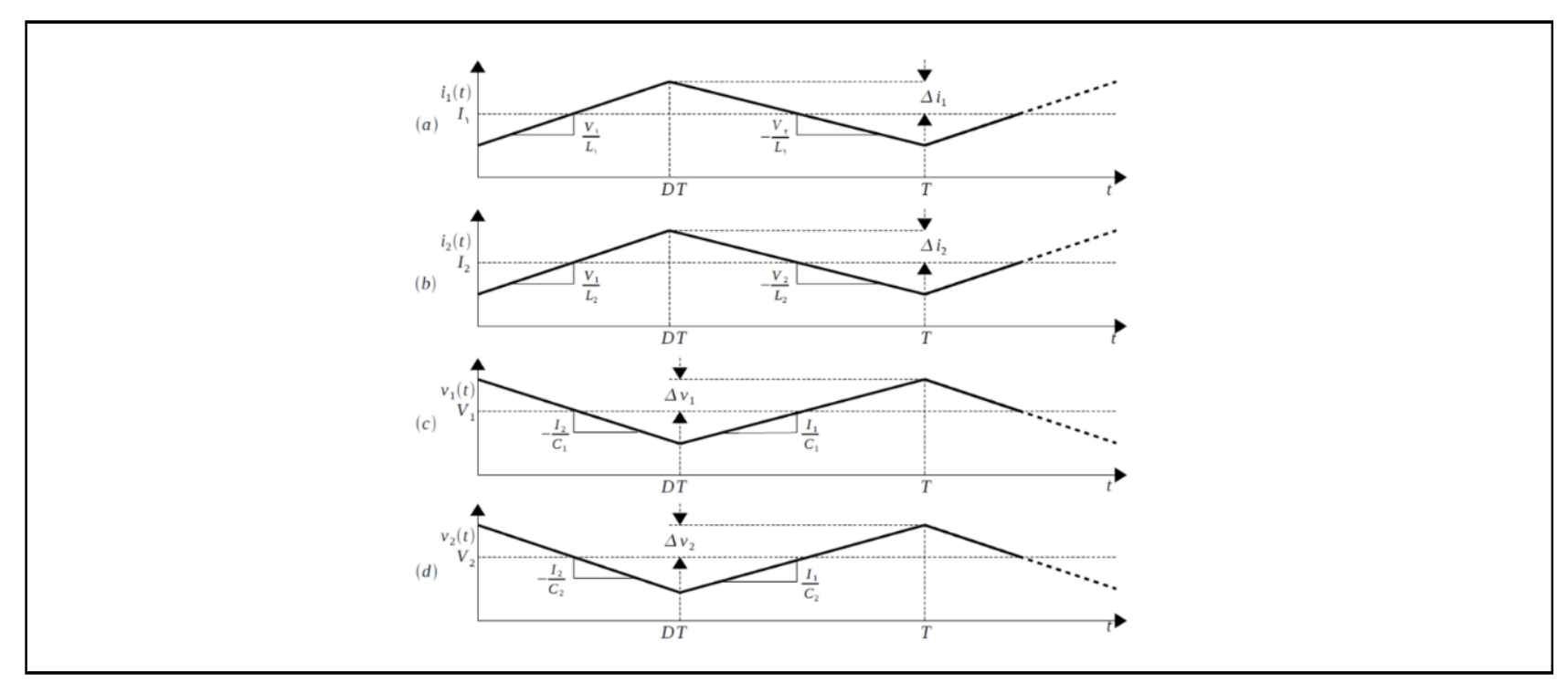

Fig. 3. Waveforms for the Sepic converter: a. coil $\mathrm{L}_{1}$ current; b. coil $\mathrm{L}_{2}$ current; c. capacitor $\mathrm{C}_{1}$ voltage; $d$. capacitor $\mathrm{C}_{2}$ voltage

Further one can equalize ripples amplitudes for coil currents and capacitors voltages by multiplying slopes in figure 3 after interval $D T / 2$. Than, using relations (6) $V_{1}, V_{2}, I_{1}$ and $I_{2}$ results: 
$\Delta v_{1}=\frac{V_{g} D^{2} T}{2 C_{1} R D^{\prime}}$

$\Delta v_{2}=\frac{V_{g} D^{2} T}{2 C_{2} R D^{\prime}}$

$\Delta i_{1}=\frac{V_{g} D T}{2 L_{1}}$

$\Delta i_{2}=\frac{V_{g} D T}{2 L_{2}}$

Using ripples amplitudes and medium values obtained one can determine maximum absolute values for capacitors voltages and coils currents, by adding ripples amplitudes to the medium values.

$$
\begin{aligned}
& v_{1, \text { max }}=V_{1}+\Delta v_{1} \\
& v_{2, \text { max }}=V_{2}+\Delta v_{2} \\
& i_{1, \text { max }}=I_{1}+\Delta i_{1} \\
& i_{2, \text { max }}=I_{2}+\Delta i_{2}
\end{aligned}
$$

With these relations one can determine the minimum values of $\mathrm{L}_{1}, \mathrm{~L}_{2}$ and $\mathrm{C}_{1}$ that guarantees to obtain the continuous conduction mode (CCM) for the converter. Limit between CCM and discontinuous conduction mode (DCM) appears when ripples amplitude is equal to continuous current components, so one equalizes continuous components in equations (6) with ripples amplitudes in equations (7) and results

$V_{g}=\frac{V_{g} D^{2} T}{2 C_{1} R D^{\prime}}$

$V_{g} \frac{D}{D^{\prime}}=\frac{V_{g} D^{2} T}{2 C_{2} R D^{\prime}}$

$\frac{V_{g}}{R}\left(\frac{D}{D^{\prime}}\right)^{2}=\frac{V_{g} D T}{2 L_{1}}$

This system solution is

$$
\begin{aligned}
& C_{1, \text { min }}=\frac{D^{2} T}{2 R D \prime} \\
& L_{1, \text { min }}=\frac{D^{2} R T}{2 D} \\
& L_{2, \text { min }}=\frac{D \prime R T}{2}
\end{aligned}
$$


Minimum value for the $C_{2}$ capacitor is given by the specification of the output voltage ripple. So, with expression of $V_{2}$ in (6) and $\Delta v_{2}$ from (7) (Erickson, R. W. \& Maksimovic, D. 2004)

$$
C_{2 \min }=\frac{V_{2}}{\Delta v_{2}} \frac{D T}{2 R D^{\prime}}=\frac{V_{\text {out }}}{\Delta v_{\text {out }}} \frac{D T}{2 R D^{\prime}}
$$

\subsection{Cuk Converter. Steady state circuit model}

Figure 4 presents the two equivalent circuits during the two states of the Cuk converter. When transistor $\mathrm{Q}_{1}$ is $\mathrm{ON}$, during period ton, coils currents increases, source $\mathrm{E}$ transfers in $\mathrm{L}_{1}$ and capacitor $\mathrm{C}_{1}$ transfers energy in $\mathrm{L}_{2}$; in the same time, $\mathrm{C}_{2}$ feeds the load, When transistor $\mathrm{Q}_{1}$ is $\mathrm{OFF}$, during toff period, coils current decrease, $\mathrm{L}_{1}$ current charges capacitor $\mathrm{C}_{1}$ and $i_{2}$ feeds the load current and charges $\mathrm{C}_{2}$.

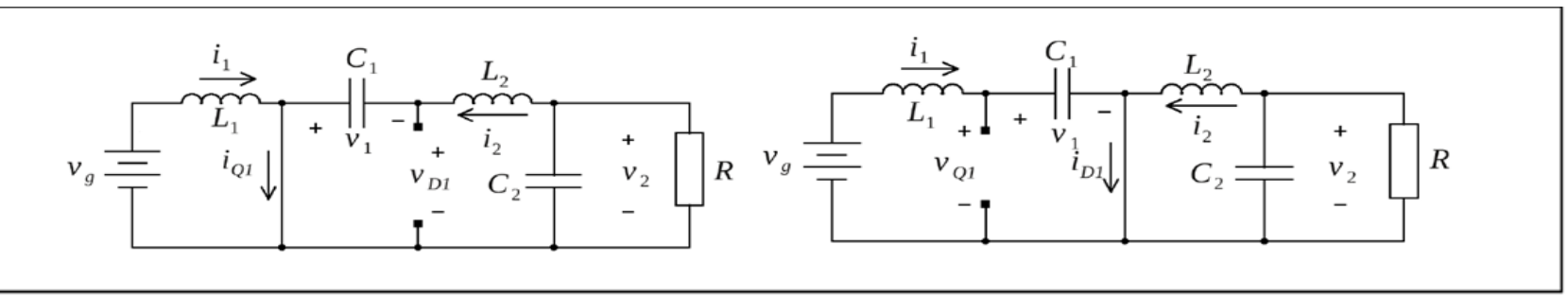

Fig. 4. Equivalent circuits for the two functioning periods of the Cuk converter

One suppose here also the commutation ripples in $i_{1}(t), i_{2}(t), v_{1}(t)$ and $v_{2}(t)$ are small with respect the continuous current components $I_{1}, I_{2}, V_{1}$ and $V_{2}$. So, one can approximate ripple as it follows (Erickson, R. W. \& Maksimovic, D. 2004).

$$
\begin{aligned}
& v_{L_{1}}=V_{g} \\
& v_{L_{2}}=V_{1}+V_{2} \\
& i_{C_{1}}=-I_{2} \\
& i_{C_{2}}=-I_{2}-\frac{V_{2}}{R}
\end{aligned}
$$

In $t_{\text {off }}$ interval, coils voltage and capacitors currents are (Delos, J. 2010; Erickson, R. W. \& Maksimovic, D. 2004)

$$
\begin{aligned}
& v_{L_{1}}=V_{g}-V_{1} \\
& v_{L_{2}}=V_{2} \\
& i_{C_{1}}=I_{1}
\end{aligned}
$$


Corcau, J. I. \& Dinca, L.: Modelling and Analysis of Symmetric Power Converter f...

$i_{C_{2}}=-I_{2}-\frac{V_{2}}{R}$

Next step consists in equalize the continuous components or mediate values for coils currents and capacitors values with equations (12) and (13). Also, one assume coils medium voltages and capacitors medium currents are 0. Results (Erickson, R. W. \& Maksimovic, D. 2004):

$<v_{L 1}>=D V_{g}+D^{\prime}\left(V_{g}-V_{1}\right)=0$

$<v_{L 2}>=D\left(V_{1}+V_{2}\right)+D^{\prime} V_{2}=0$

$<i_{C 1}>=D\left(-I_{2}\right)+D^{\prime} I_{1}=0$

$<i_{C 2}>=-I_{2}-\frac{V_{2}}{R} D=0$

From these equations one obtains the continuous components

$V_{1}=\frac{V_{g}}{D^{\prime}}$

$V_{2}=-V_{g} \frac{D}{D^{\prime}}$

$I_{1}=I_{2} \frac{D}{D^{\prime}}=\frac{V_{g}}{R}\left(\frac{D}{D^{\prime}}\right)^{2}$

$I_{2}=\frac{V_{2}}{R}=\frac{V_{g}}{R} \frac{D}{D^{\prime}}$

One observes equations obtained for continuous component of the output voltage $V_{2}$ and coils $I_{1}$ and $I_{2}$ are the same as those of SEPIC converter.

Because both converters are analogical, $V_{1}$ ripples and currents $I_{1}$ and $I_{2}$ ripples are the same as those for SEPIC converter. The most relevant difference between these converters is the output capacitor. In Cuk converter, $L_{2}$ coil and $C_{2}$ capacitor are always connected to the load. So, the output capacitor filters only the alternative component.

Output voltage ripple is (Erickson, R. W. \& Maksimovic, D. 2004):

$\Delta v_{2}=\frac{\Delta i_{2} T}{8 C_{2}}=\frac{V_{2} D T^{2}}{16 C_{2} L_{2}}$

$C_{2}$ capacitor value is determined by the voltage ripple requirements, so equation (16) can be written as

$$
C_{2}=\frac{V_{2}}{\Delta v_{2}} \frac{D^{\prime} T^{2}}{16 L_{2}}
$$


DC conversion ratio for Cuk converter is $M(D)=-\frac{V_{2}}{V_{g}}=-\frac{D}{D^{\prime}}=-\frac{D}{1-D}$.

\section{Components dimensioning}

For converter components dimensioning one assumed the following hypothesis:

- Absolute output voltage is $270 \mathrm{~V}$

- Maximum load in CCM is a half of fuel cell power

- Maximum peak-to-peak ripple of the output voltage is 5\% from the nominal voltage

- Components have to support the fuel cell power $P_{F C}=16.5 \mathrm{~kW}$ at input voltage $V_{\mathrm{g}}=455 \mathrm{~V}$

Determined values for the passive components are presented in the following table:

\begin{tabular}{|c|c|c|c|c|}
\hline & $L_{1}[\mu \mathrm{H}]$ & $L_{2}[\mu \mathrm{H}]$ & $C_{1}[\mu \mathrm{F}]$ & $C_{2}[\mu \mathrm{F}]$ \\
\hline SEPIC & 233 & 120 & 3 & 30 \\
\hline Cuk & 233 & 120 & 3 & 3.7 \\
\hline
\end{tabular}

Tab. 1. The passive components

\section{SEPIC small signal model and transfer functions}

In figure 5 is presented the small signal model for SEPIC converter. Based on this model one can deduce the state equations for its variables:

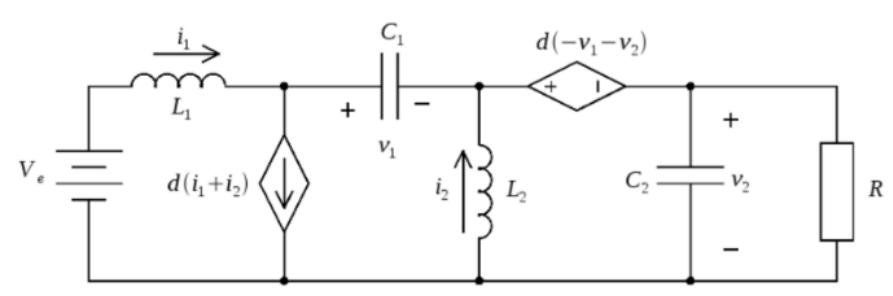

Fig. 5. Small signal model - Sepic (Delos, J. 2010)

$L_{1} \frac{d i_{1}}{d t}=v_{g}-\left(v_{1}+v_{2}\right) d^{\prime}$

$C_{1} \frac{d v_{1}}{d t}=i_{1} d^{\prime}-i_{2} d$

$L_{2} \frac{d i_{2}}{d t}=v_{1} d-v_{2} d^{\prime}$

$C_{2} \frac{d v_{2}}{d t}=\left(i_{1}+i_{2}\right) d^{\prime}-\frac{v_{2}}{R}$

Applying the averaged model and considering variables composed from contoinuous component $(X)$ and alternating component $(\hat{x})$, first equation (18) becomes $L_{1} \frac{d\left(I_{1}+\hat{l}_{1}\right)}{d t}=\left(V_{g}+\hat{v}_{g}\right)-\left(V_{1}+\hat{v}_{1}+V_{2}+\hat{v}_{2}\right)\left(D^{\prime}+\hat{d}^{\prime}\right)$. This equation contains 
continuous components as $\left(V_{g}-V_{1} D^{\prime}-V_{2} D^{\prime}\right), 1$ st order a.c. terms $\hat{v}_{g}-\hat{v}_{1} D^{\prime}-\hat{v}_{2} D^{\prime}-$ $\hat{d}^{\prime} V_{1}-\hat{d}^{\prime} V_{2}$ and $2^{\text {nd }}$ order a.c. terms $\hat{d}^{\prime} \hat{v}_{1}+\hat{d}^{\prime} \hat{v}_{2}$. Neglecting second order terms and after some calculus results the four equations in imaginary domain $s$ (19) (Delos, J. 2010)

$$
\begin{aligned}
& s L_{1} \hat{\imath}_{1}=\hat{v}_{g}-\hat{v}_{1} D^{\prime}-\hat{v}_{2} D^{\prime}+\hat{d} V_{g}\left(1+\frac{D}{D^{\prime}}\right) \\
& s L_{2} \hat{\imath}_{2}=\hat{v}_{1} D-\hat{v}_{2} D^{\prime}+\hat{d} V_{g}\left(1+\frac{D}{D^{\prime}}\right) \\
& s C_{1} \hat{v}_{1}=\hat{\imath}_{1} D^{\prime}-\hat{\imath}_{2} D-\hat{d} \frac{V_{g}}{R} \frac{D}{D^{\prime 2}} \\
& s C_{2} \hat{v}_{2}=\hat{\imath}_{1} D^{\prime}+\hat{\imath}_{2} D^{\prime}-\frac{\hat{v}_{2}}{R}-\hat{d} \frac{V_{g}}{R} \frac{D}{D^{\prime 2}}
\end{aligned}
$$

Due to the system complexity one estimate the control-output transfer function using MATLAB. Transfer function results as it follows

$$
H(s)=\frac{\hat{v}_{2}(s)}{\widehat{d}(s)}=\frac{s^{3} A_{3}+s^{2} A_{2}+s A_{1}+A_{0}}{s^{4} B_{4}+s^{3} B_{3}+s^{2} B_{2}+s B_{1}+B_{0}}
$$

with coefficients

$$
\begin{aligned}
& A_{3}=-C_{1} D L_{1} L_{2} V_{g} \\
& A_{2}=C_{1}\left(L_{1}+L_{2}\right) R D^{\prime} V_{g} \\
& A_{1}=-V_{g} L_{1} D^{3}-D^{\prime} V_{g} L_{1} D^{2} \\
& A_{0}=V_{g} D^{2} D^{\prime 2} R+2 V_{g} R D D^{\prime 3}+V_{g} R D^{\prime 4} \\
& B_{4}=C_{1} C_{2} L_{1} L_{2} R D^{\prime} \\
& B_{3}=C_{1} L_{1} L_{2} D^{\prime 2} \\
& B_{2}=R\left[C_{1} D^{\prime 2}\left(D^{\prime 2} L_{1}+D^{\prime 2} L_{2}\right)+C_{2} D^{\prime 2} R\left(L_{1} D^{2}+L_{2} D^{\prime 2}\right)\right] \\
& B_{1}=\left(L_{1} D^{2}+L_{2} D^{\prime 2}\right) D^{\prime 2} \\
& B_{0}=D^{\prime 2}\left(R D^{\prime 2} D^{2}+2 R D D^{\prime 3}+R D^{\prime 4}\right)
\end{aligned}
$$

Figure 6 presents the Bode diagrams for the transfer function when converter is at maximum load $(16.5 \mathrm{~kW})$ and at half load $(8.25 \mathrm{~kW})$; between these limits, converter operates in CCM, so, deduced transfer function is valid; figure 7 presents zeros and poles map in $s$ plane for the transfer function control-output of Sepic converter. Some disadvantages of Sepic topology consist in difficult control. Due to the inductors that are electromagnetic energy storage elements, system order is high and produces two resonance frequencies. After the second resonance frequency it is impossible to control 
the converter due to the great phase shift. In the presented example phase shift attends $630^{\circ}$ after this second resonance frequency. These values were obtained after MATLAB simulation of the mathematical model.
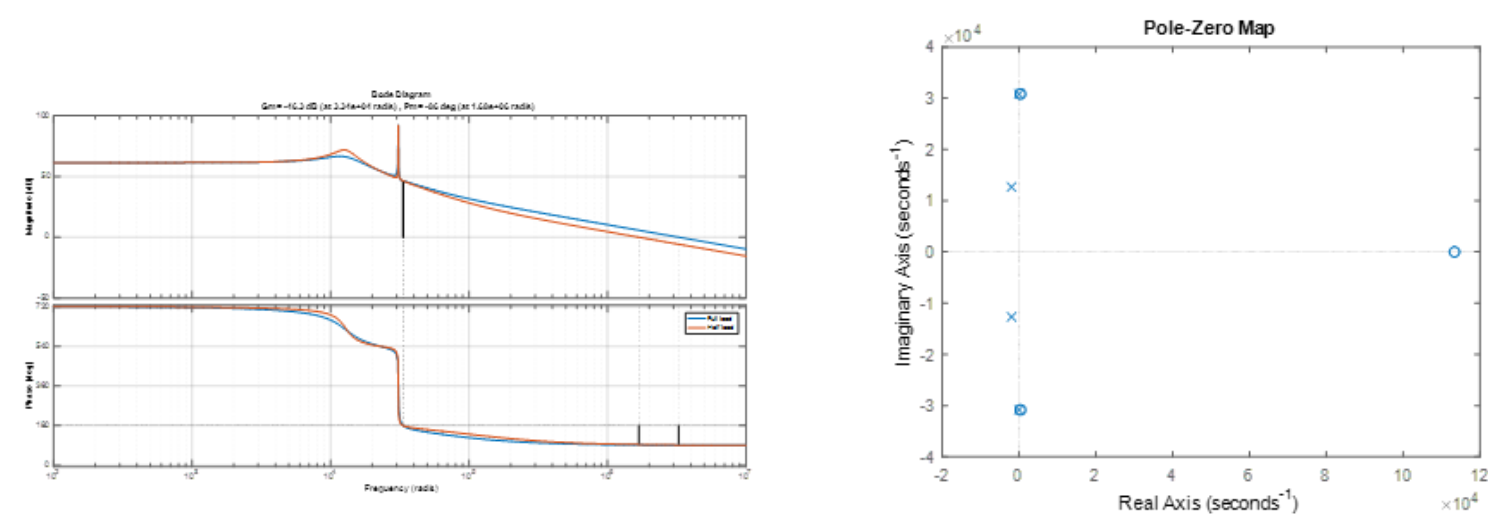

Fig. 6. Bode diagram of the Sepic Fig. 7. Poles-Zeros map in the s-plane for converter transfer function the output-control transfer function of the SEPIC converter

\section{Cuk small signal model and transfer functions}

In figure 8 is shown the small signal model for Cuk converter; based on this model one write equations for the state variables as it follows:

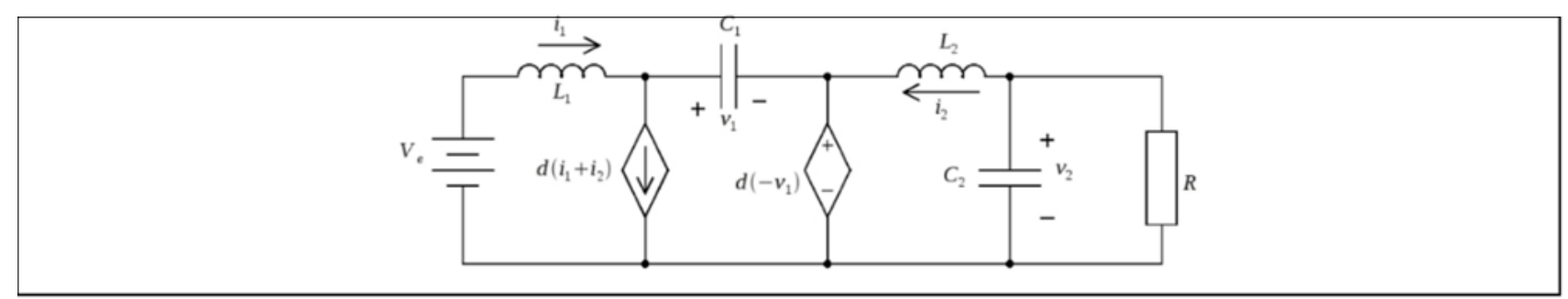

Fig. 8. Small signal model - Cuk (Delos, J. 2010)

$$
\begin{aligned}
& L_{1} \frac{d i_{1}}{d t}=v_{g}-v_{1} d^{\prime} \\
& C_{1} \frac{d v_{1}}{d t}=i_{1} d^{\prime}-i_{2} d \\
& L_{2} \frac{d i_{2}}{d t}=v_{1} d+v_{2} \\
& C_{2} \frac{d v_{2}}{d t}=-i_{2}-\frac{v_{2}}{R}
\end{aligned}
$$

Using the same technique as in Sepic converter case results $s$-plane equations as it follows:

$$
s L_{1} \hat{\imath}_{1}=\hat{v}_{g}-\hat{v}_{1} D^{\prime}+\hat{d} \frac{V_{2}}{D^{\prime}}
$$


Corcau, J. I. \& Dinca, L.: Modelling and Analysis of Symmetric Power Converter f...

$s L_{2} \hat{l}_{2}=\hat{v}_{2}+\hat{v}_{1} D+\hat{d} \frac{V_{g}}{D^{\prime}}$

$s C_{1} \hat{v}_{1}=\hat{\imath}_{1} D^{\prime}-\hat{\imath}_{2} D-\hat{d} \frac{V_{g}}{R} \frac{D}{D^{\prime 2}}$

$s C_{2} \hat{v}_{2}=-\hat{\imath}_{2}-\frac{\hat{v}_{2}}{R}$

Taking into account the system complexity on use again MATLAB to deduce controloutput transfer function. Transfer function results

$H(s)=\frac{\hat{v}_{2}(s)}{\widehat{d}(s)}=\frac{s^{2} A_{2}+s A_{1}+A_{0}}{s^{4} B_{4}+s^{3} B_{3}+s^{2} B_{2}+s B_{1}+B_{0}}$

where coefficients are:

$A_{2}=-V_{g} C_{1} L_{1} L_{2} D^{\prime}$

$A_{1}=V_{g} L_{1} D^{2}$

$A_{0}=-V_{g} R D D^{\prime 2}-V_{g} R D^{\prime 3}$

$B_{4}=D^{\prime 2} C_{1} C_{2} L_{1} L_{2} R$

$B_{3}=D^{\prime 2} C_{1} L_{1} L_{2}$

$B_{2}=D^{\prime 2} R\left(L_{1} C_{1}+C_{2}\left(L_{1} D^{2}+L_{2} D^{\prime 2}\right)\right)$

$B_{1}=D^{\prime 2}\left(L_{1} D^{2}+L_{2} D^{\prime 2}\right)$

$B_{0}=D^{\prime 4} R$

Figure 9 presents Bode diagram for the control-output transfer function when Cuk converter is at maximum load $(16.5 \mathrm{~kW})$ and at half load $(8.25 \mathrm{~kW})$; between these limits converter operates in CCM, so deduced transfer function can be used. Figure 10 presents zeros and poles map in $s$ plane for control-output transfer function of Cuk converter.

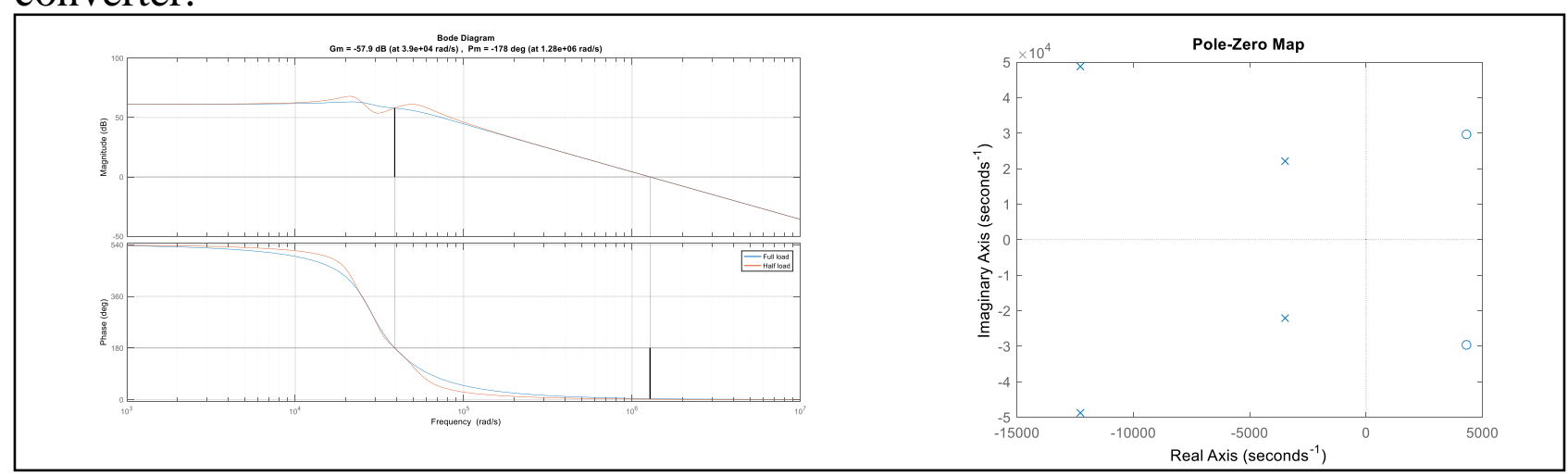

Fig. 9. Bode diagram of the Cuk converter transfer function

Fig. 10. Poles-Zeros map in the s-plane the output-control transfer of the SEPIC converter

\section{Closed Loop Controller Design}


In figure 11a is presented functional block diagram of the feedback system and in figura $11 \mathrm{~b}$ is presented block diagram of the closed loop converters. Diagram contains symmetric converter consisting in Sepic converter and Cuk converter that provides +270 VDC and respectively -270 VDC. Output voltage is detected and attenuated by the $\mathrm{H}(\mathrm{s})$ sensor and after that is compared to reference voltage Vref. Error signal is amplified by the compensation network $\mathrm{Gc}(\mathrm{s})$, and pulse width modulation close the control loop. The two PWMs are $180^{\circ}$ phase shifted in order to produce the symmetric interleaved concept, that reduce current ripple in DC bus. Finally, the PWM signals are applied to IGBTs.

The pulse-width modulator block produces a logic signal $\delta(t)$ that commands the converter power transistor to switch on and off. The logic signal $\delta(t)$ is periodic, with frequency f and duty cycle $d(t)$.

Stability is another important issue in feedback systems. Adding a feedback loop can cause an otherwise well-behaved circuit to exhibit oscillations, ringing and overshoot, and other undesirable behavior. The simple phase margin criterion for assessing stability is used here. When the phase margin of the loop gain is positive, then the feedback system is stable. Moreover, increasing the phase margin causes the system transient response to be better behaved, with less overshoot and ringing (Erickson, R. W. \& Maksimovic, D. 2004; Thounthong, P.; Sethakul, P. \& Davat, B. 2009).

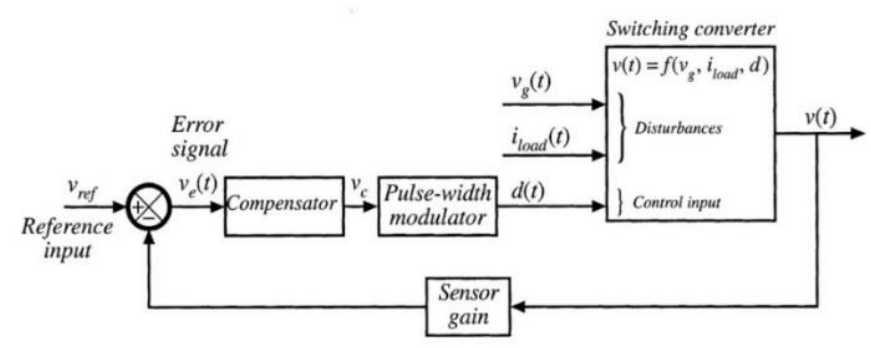

Fig. 11a. Functional block diagram of the feedback system (Erickson, R. W. \& Maksimovic, D. 2004)

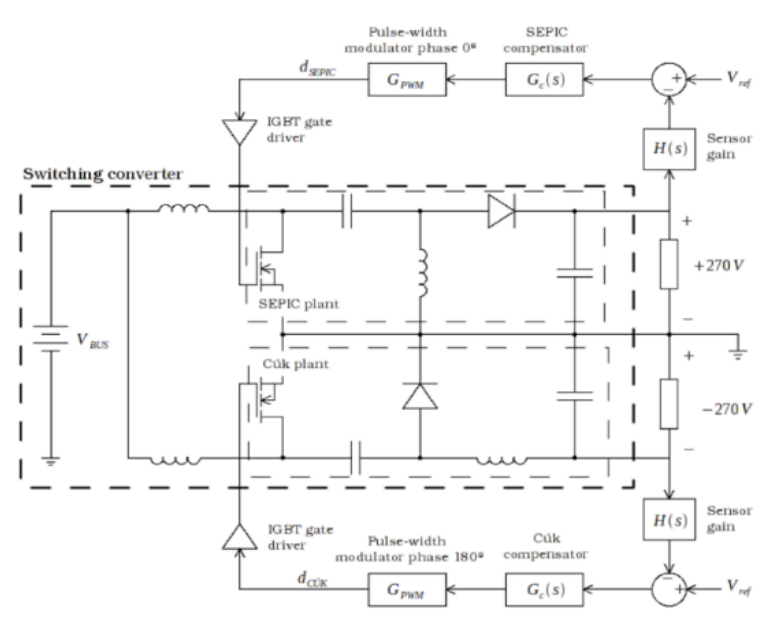

Fig. 11b. Block diagram of the symmetric converter feedback (Delos, J. 2010)

In previous sections, one identified the poles and zeros of the control-output transfer function, for both converters. In fact, both converters have an almost identical 
transfer function. A complex pole is about $4.7 \mathrm{kHz}$, and a complex zero and a complex pole are about $1.9 \mathrm{kHz}$, for both converters. So, the same compensation network can be used for both converters. One have to determine the gain for the feedback $H(s)$. Choose value for voltage reference, $V_{r e f}$, is $3 \mathrm{~V}$, so the gain of the SEPIC converter sensor is

$H(s)=\frac{V_{r e f}}{V_{o}}=\frac{3}{270}=\frac{1}{90}$

Linear variable voltage generator delivers a signal with amplitude 1 , so the open loop transfer function is

$T(s)=H(s) G_{c}(s) G_{\text {plant }}(s)$

Choose transfer function for the for the for both compensation network is:

$G_{c}(s)=K \frac{1}{s^{2}} \frac{\frac{s}{\omega_{1}}+1}{\left(\frac{s}{\omega_{0}}\right)^{2}+2 \varsigma \frac{s}{\omega_{0}+1}+1}$

Double pole in origin cancels the stationary error; complex zero at $\omega_{1}=60 \mathrm{~Hz}$ grows the amplitude bandwidth in order to obtain a positive phase margin and complex pole at $\omega_{0}=400 \mathrm{~Hz}$ and $\xi=1$ decrease the converter resonance frequency that can produce instability and also improves the filtering of converter commutation frequency; gain $K=10$, characterises the system dynamic. In figure 12 is shown the compensation network Bode diagram.

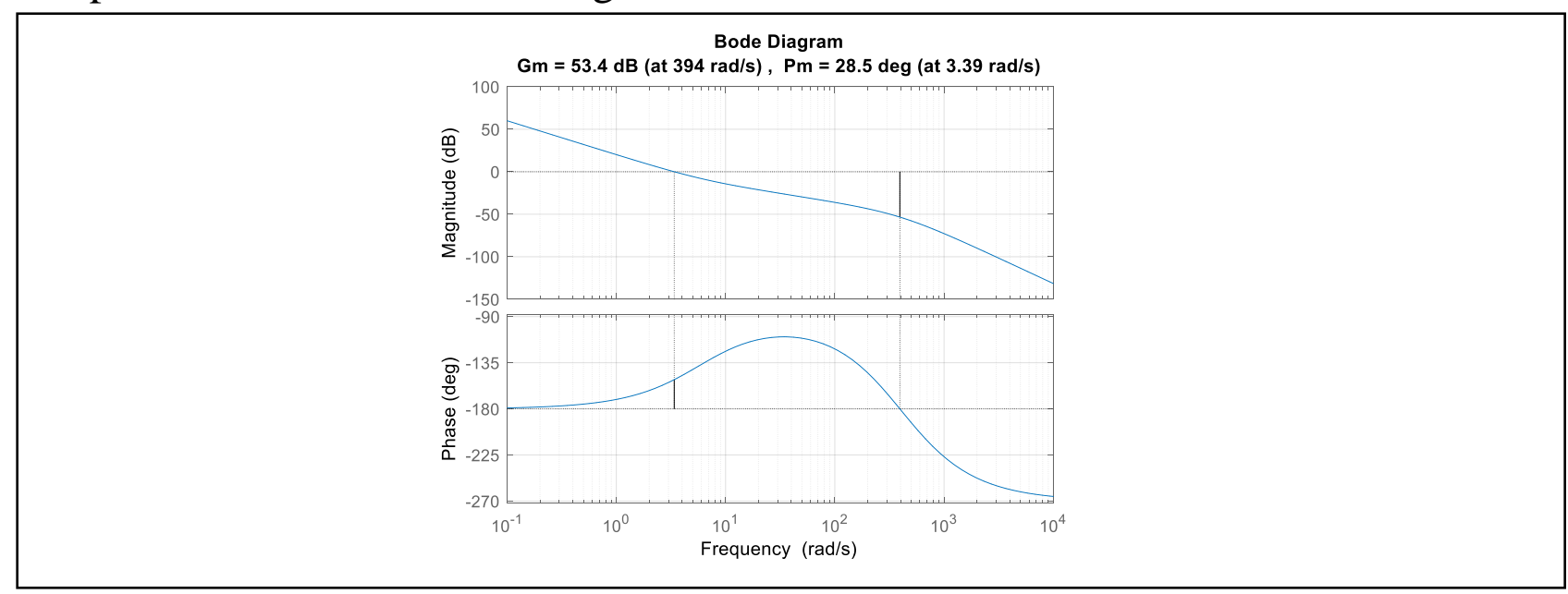

Fig. 12. Bode diagram of the transfer function for compensation networks 
Proposed compensation network follows to attenuate the resonance peaks of the open loop converter, and, in same time, to diminish the commutation converter noise. This fact impose to have a sufficient cutting frequency, $f_{c}$, for the loop gain $T(s)$ in order to obtain a sufficient attenuation to avoid the second resonance peak traversing 0 $\mathrm{dB}$ amplitude. So, $f_{c}$ is small, that implies a sluggish dynamic of the symmetric converter response. In figure 13a is presented the gain of Sepic converter loop and in figure 13.b the gain for the Cuk converter loop. One observes both converters have almost identical characteristics. Converter gain band GMB is $30.9 \mathrm{~dB}$ at $389 \mathrm{rad} / \mathrm{s}$ and phase margin is $68.5^{\circ}$ at $22.1 \mathrm{rad} / \mathrm{s}$.

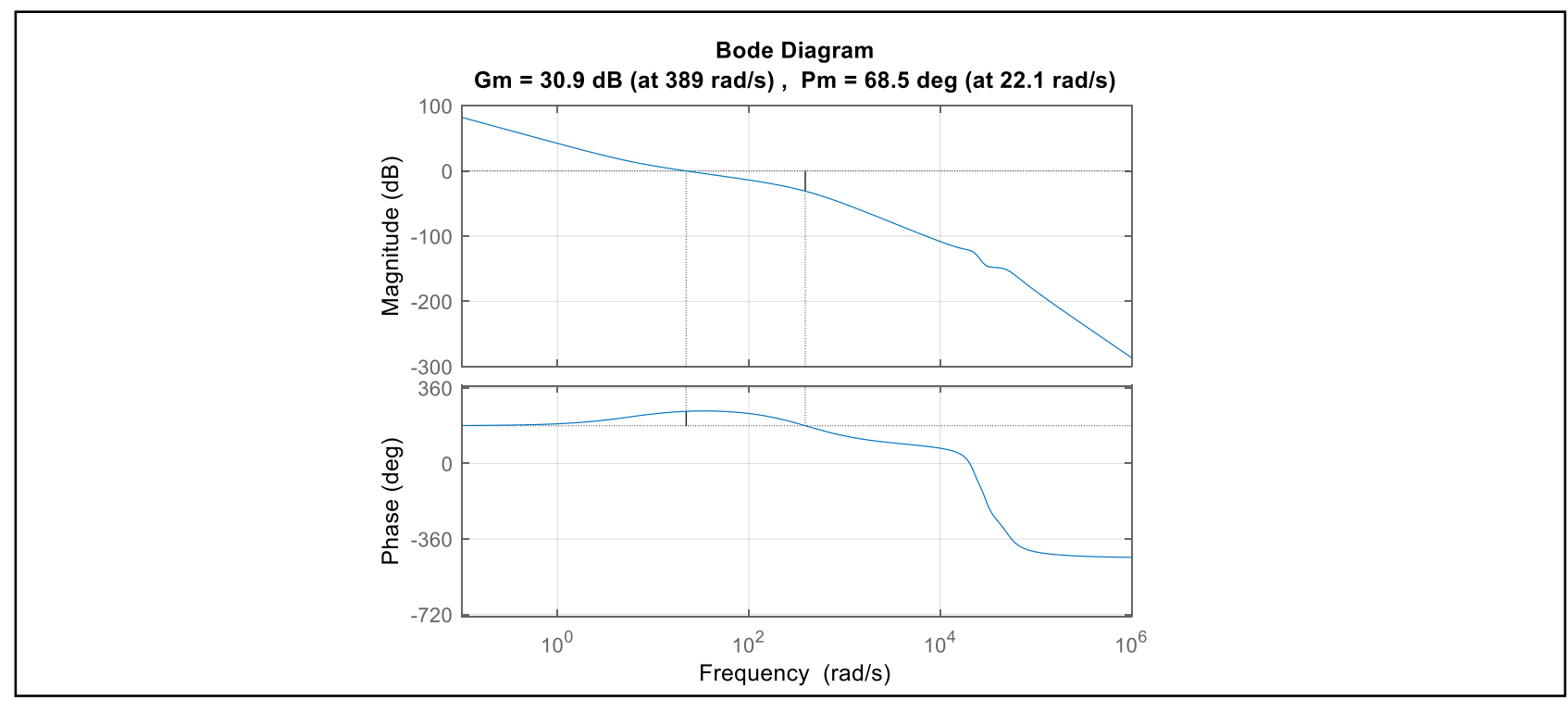

Fig. 13a. Bode diagram of the Sepic converter gain-loop

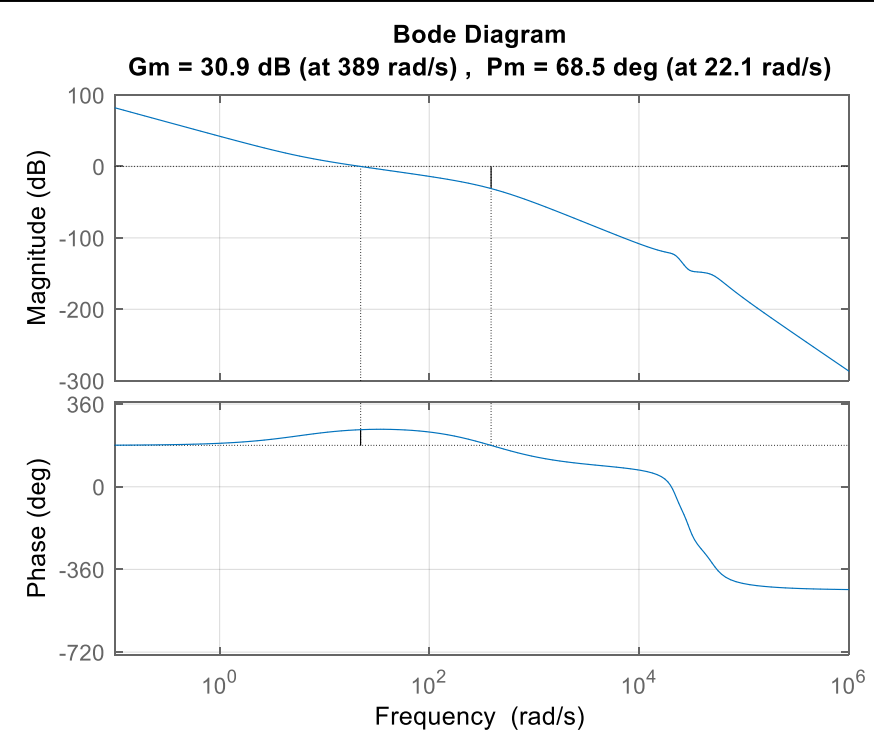

Fig. 13b. Bode diagram of the Cuk converter gain-loop

In figure 14 is presented the closed loop model for Sepic converter implemented in Simulink SimPowerSys and in figure 15 is presented the closed loop model for Cuk converter implemented also in SimpPowerSys. 


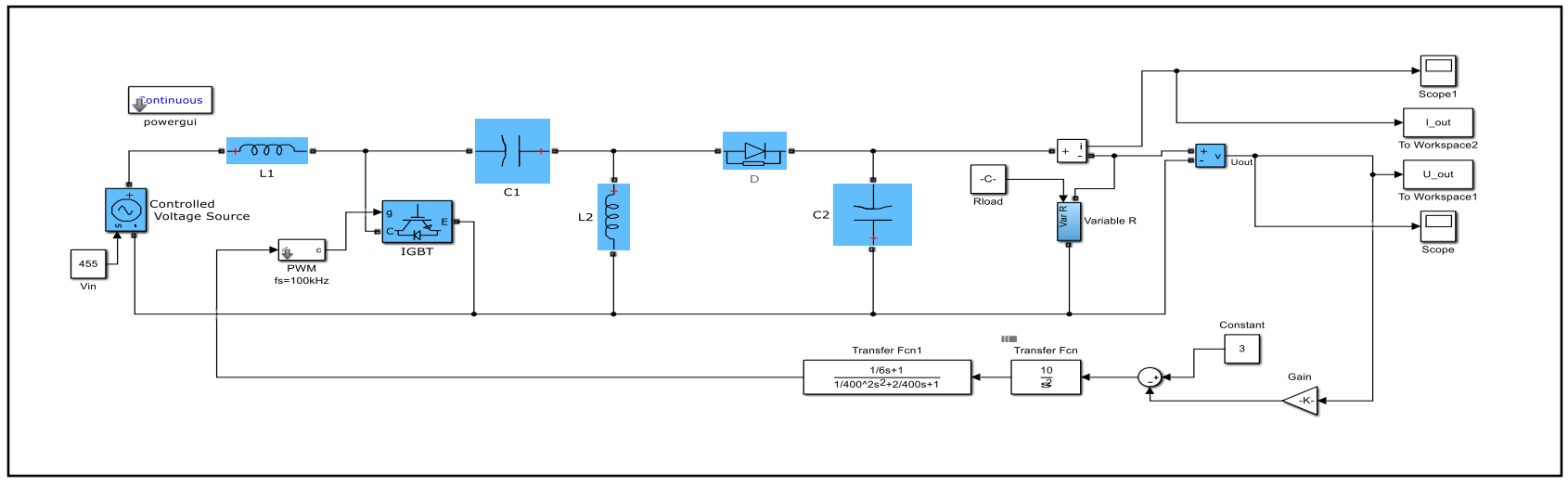

Fig. 14. Matlab/Simulink model for Sepic converter

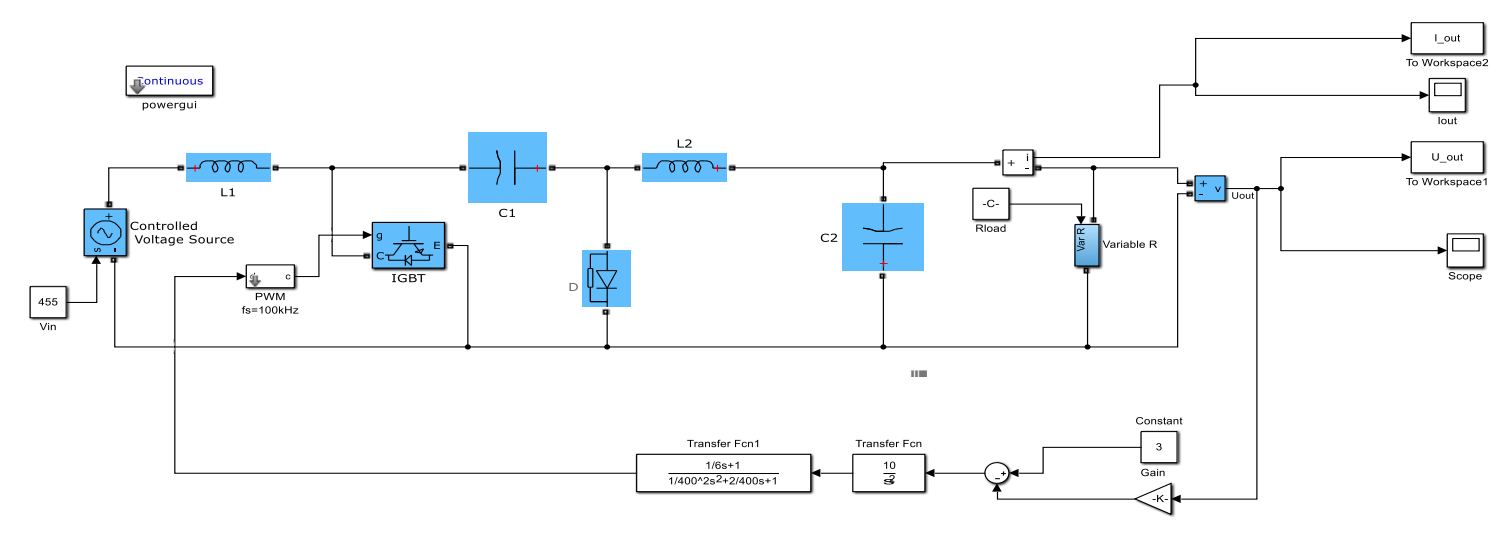

Fig. 15. Matlab/Simulink model for Cuk converter

After numeric simulations for both converters one obtained the following time responses. Converters were simulated at maximum load of $16.5 \mathrm{~kW}$. In figure $16 \mathrm{a}$ is presented time variation of the Sepic converter output voltage and in figure $16 \mathrm{~b}$ ia presented the output voltage ripple for Sepic converter. Figure 17a presents time variation of the Sepic converter output current and in figure 17b output current ripple.
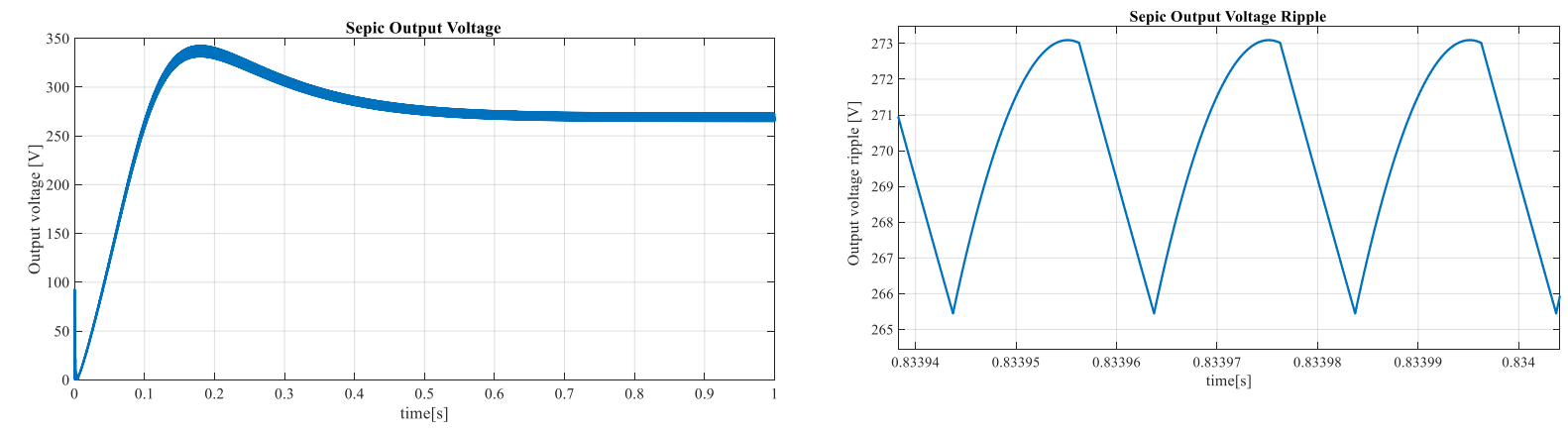

Fig. 16a. Simulation results: Output voltage Fig. 16b. Detail of output voltage ripple 


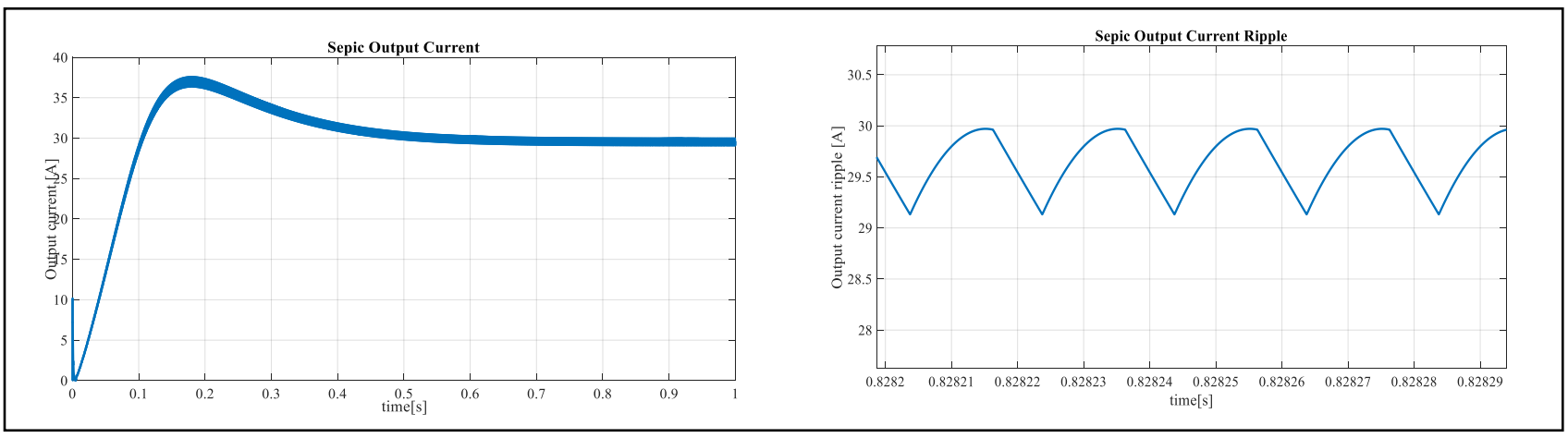

Fig. 17a. Simulation results: Output current Fig. 17b. Detail of output current ripple

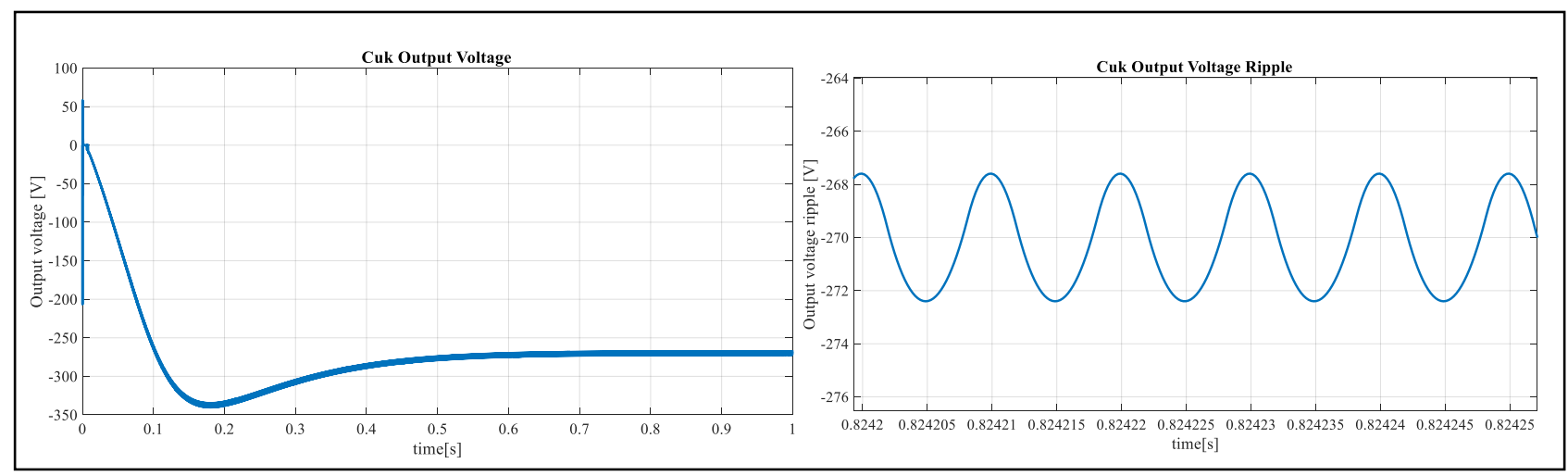

Fig. 18a. Simulation results: Output voltage Fig. 18b. Detail of output voltage ripple

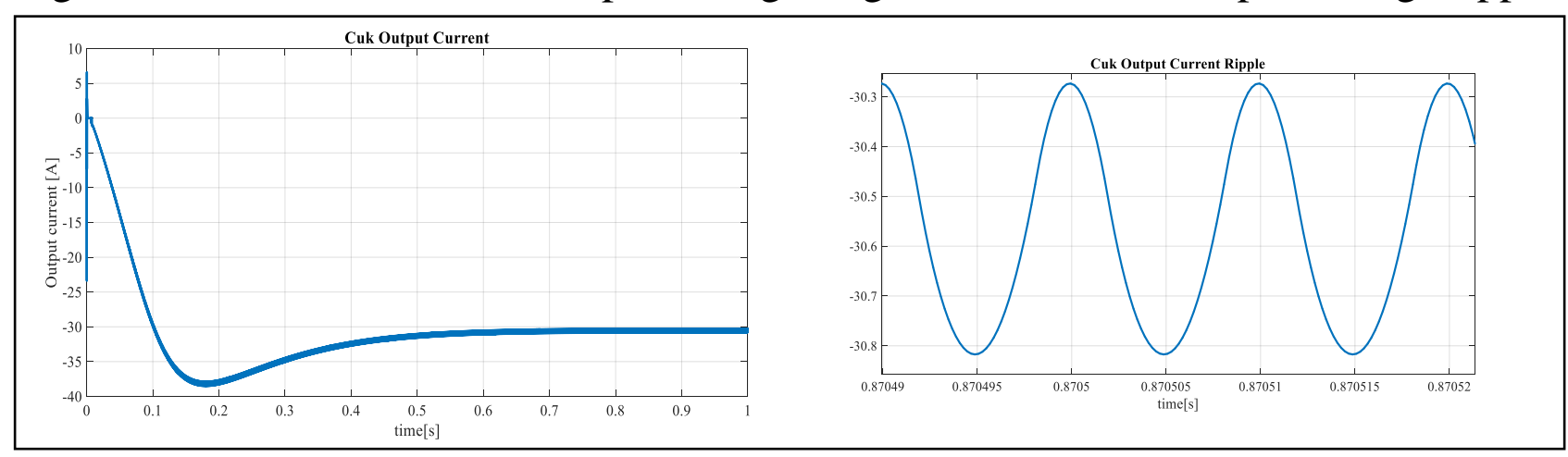

Fig. 19a. Simulation results Output current Fig. 19b. Detail of output current ripple

Figures 16 and 18 show output voltages for both converters at stabilized value \pm 270 VDC. One observes closed loop system stabilizes both outputs in the functioning point, even the converter is in DCM. Transitory regime lasts for about $600 \mathrm{~ms}$ and the dynamic response is correct and identical for both outputs. Output voltage ripple in figure $16 \mathrm{~b}$ is $7.8 \mathrm{~V}$ peak-to-peak, that means $2.8 \%$ from output voltage and $2.4 \mathrm{~V}$ peak-to-peak for negative voltage, that means $0.89 \%$ from output voltage.

\section{Conclusion}

Worldwide tendency is to build more silent and less polluting aircraft. In this context, one follows to develop new technologies, in order to drop the total costs and fuel consumption. 
More Electric Aircraft concept issued to replace the classical systems with electric systems. Power electronics development in the last years lead to more sophisticated static power converters on board.

This paper focuses on the design of a power converter that contains in fact two separate converters, one Sepic type and one Cuk type to obtain a \pm 270 VDC symmetric stabilised voltage. One deduced the functioning equations for each converter, one dimensioned their components and finally one validated the design by numerical simulation in Matlab/Simulink. Simulation results show a good functioning for both converters.

\section{References}

Ayres, J.; Richards, R.; et al (2006). Air Pollution and Health, Imperial College Chen, J.; Wang, C. \& Jie Chen. (2018) Investigation on the Selection of Electric Power System Architecture for Future More Electric Aircraft. IEEE Transactions On Transportation Electrification

Corcau, J. I. \& Dinca, L. (2012). On using PEMFC for electrical power generation on More Electric Aircraft. International Journal of Electronics and Electrical Engineering Delos, J. (2010). Symmetric \pm 270 V DC Power Supply of a Universal Power Converter for Airborne Applications. Polytechnic Institute of New York University, Master Thesis

Eid, A.; El-Kishky, H. et al. (2010). Modeling and characterization of an aircraft electric power system with a fuel cell-equipped APU connected at HVDC bus. International Power Modulator and High Voltage Conference, Atlanta

Erickson, R. W. \& Maksimovic, D. (2004) Fundamentals of Power Electronics SECOND EDITION University of Colorado Boulder, Colorado, ISBN 978-0-30648048-5 (eBook)

Kwon, J. M. \& Kwon, B.-H. (2009). High step-up active-clamp converter with inputcurrent doubler and output-voltage doubler for fuel cell power systems. IEEE Transactions on Power Electronics

Liu, C.; Johnson, A.; \& Lai, J.-S. (2004). A novel three-phase high-power soft switched $\mathrm{dc} / \mathrm{dc}$ converter for low voltage fuel cell applications. In Applied Power Electronics Conference and Exposition Nineteenth Annual IEEE

Rahimi, A. M \& Emadi, A. (2009). Active Damping in DC/DC Power Electronic Converters: A Novel Method Overcome the Problems of Constant Power Loads. IEEE Transactions On Industrial Electronics

Thounthong, P.; Sethakul, P.; Rael, S. \& Davat, B. (2009). Fuel cell current ripple mitigation by interleaved echnique for high power applications. In Industry Applications Society Annual Meeting

Thounthong, P.; Sethakul, P. \& Davat, B. (2009.) Modified 4-phase interleaved fuel cell converter for high- power high-voltage applications. In Industrial technology, ICIT Corcau, J.I. \& Dinca, L. (2015). Numerical model and experimental tests for dc to dc boost converter. DAAAM International Scientific Book 2015, pp. 067-086, ISBN 9783-902734-05-1. 